\title{
جماليات القصيدة الرقمية التفاعلية - المعسوعة الشعرية أنموذجا
}

$$
\begin{aligned}
& \text { إعداد } \\
& \text { د/ عبد الرحمن خليفة الملحم } \\
& \text { المملكة العربية السعودية - جامعة الإمام محمد بن سعود الإسلامية }
\end{aligned}
$$

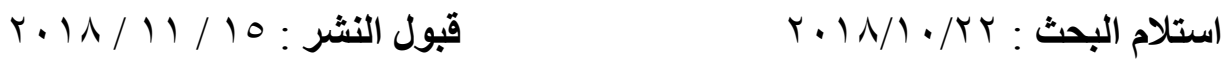

\section{ملخص الدراسة}

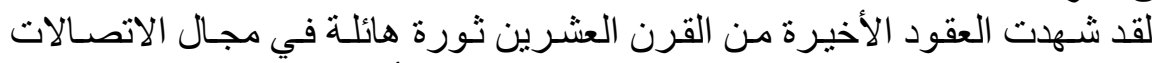

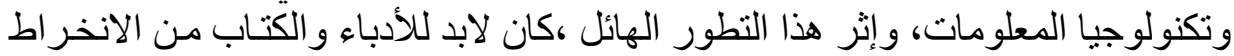

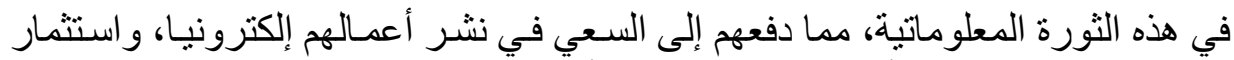

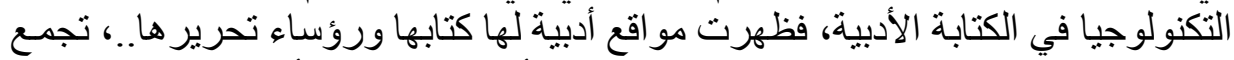

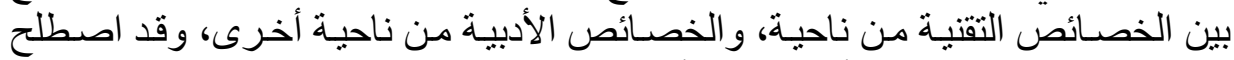

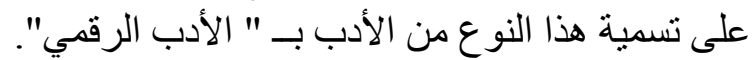

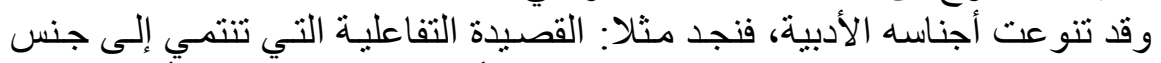

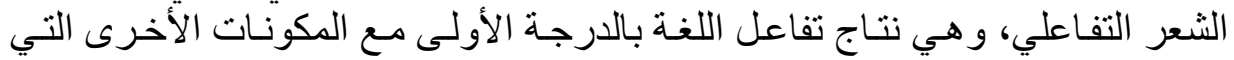

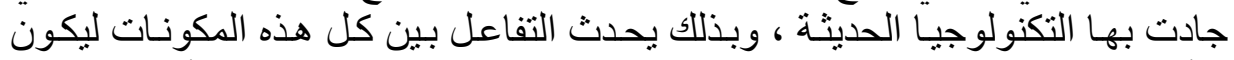

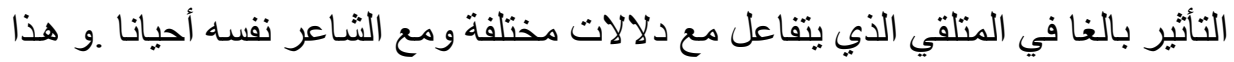

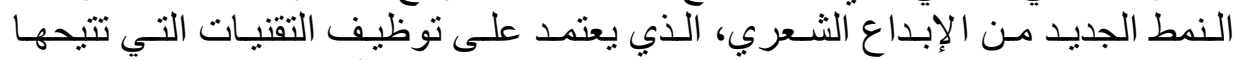

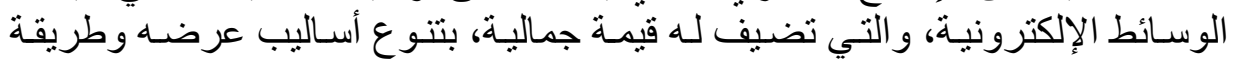

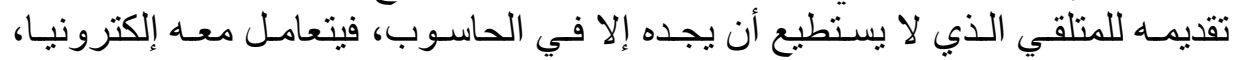

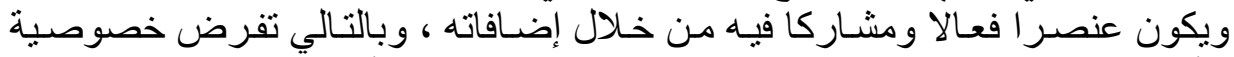

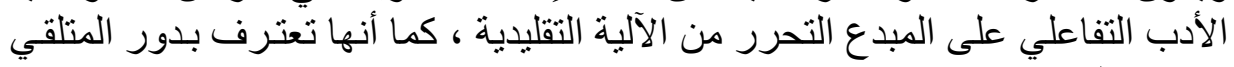

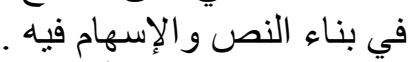
الكلمات المفتاحية: الأدب الرقميـ الوسائط الإلكترونية ـ القصيدة التفاعلية ـ المتلقي. Abstract:

The last decades of the twentieth century witnessed a tremendous revolution in the field of communications and information technology. After this tremendous development, writers and writers had to be involved in this information revolution. This led them to seek to publish their works electronically and to invest in technology in literary writing. Its writers and editors, combining 


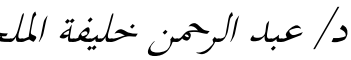

technical characteristics with literary characteristics. It is the result of the interaction of the language primarily with the other components of modern technology, and thus the interaction between all these components to be very influential in the recipient, which interacts with different connotations and with The poet himself sometimes. This new style of poetic creativity, which depends on the use of technologies offered by electronic media, which adds value to the aesthetic, the variety of presentation methods and the way it is presented to the recipient, which can not be found only in the computer, Effective and participative through its additions, and therefore the privacy of interactive literature imposes on the creator the freedom from the traditional mechanism, and recognizes the role of the recipient in building the text and contribute to it .

key words: Digital Literature - Electronic Media - Interactive Poem - Recipient.

شهدت الساحة الأدبية حر اكا ثقافيا نوعيا، من خلال محاكاة تجارب جديدة في الكتابة

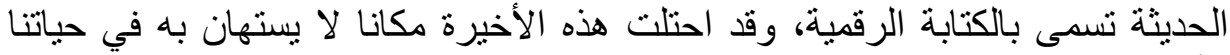
الأدبية و الثقاقبة.

منذ عثرون عاما ظهر في ساحتنا الأدبية إنتاج أدبي جديد يقر أ على شاثنة الكمبيوتر، ومن خصائصه أنه يقوم بدمج الوسائط الإلكترونية المتعددة، نصية وصية وصوتية وصوية وصورية

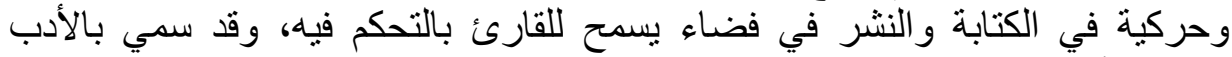
الرقمي أو التفاعلي الذي يعتمد على الوسائل الحديثة في الكتابة، والاستفادة من المعطبات التكنولوجية وثورة المعلومات المعاصرة.

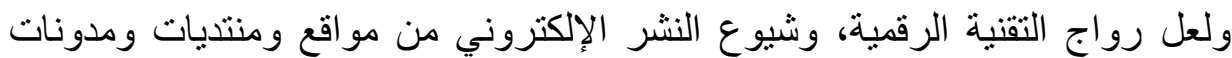

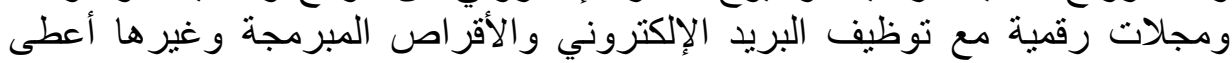

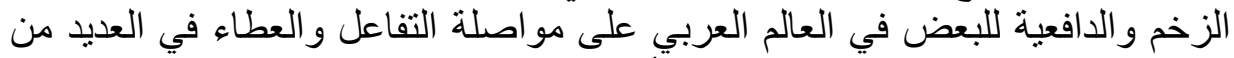
المجالات كما في الإبداع وصور الكتابة بأنو اعها الثعرية و النتية الثرية.

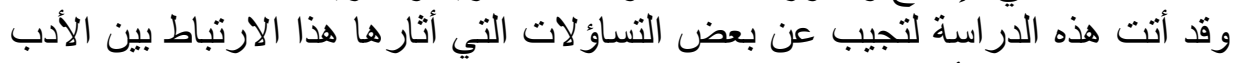
و التكنولوجيا، ومن أهمها: 
ما المقصود بالأدب الرقمي؟ ، و هل يمكن القول أن نشهد حلقة جديدة من حلقات تطور

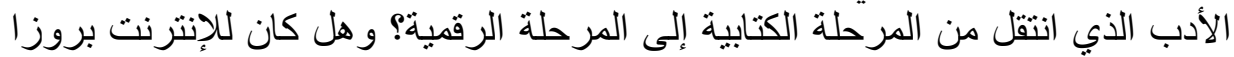

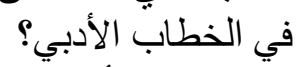
جميع هذه الأسئلة حاولنا الإجابة عنها بالفحص والفيكة التهحيص، مستتدين في دراستتا هذه

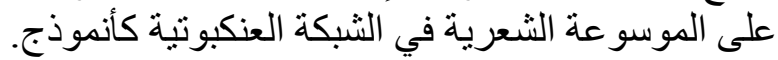

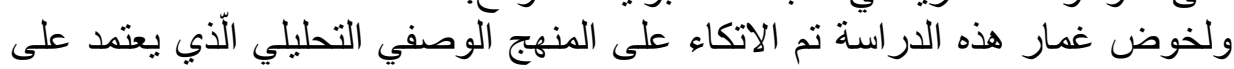

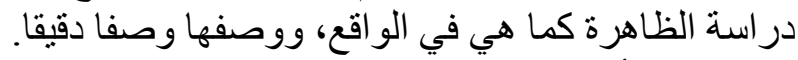
1-تعريف الأدب الرقمي:

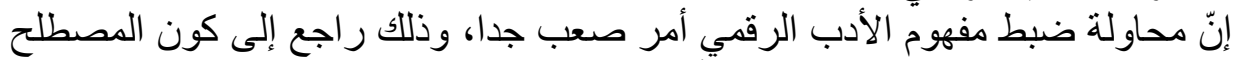

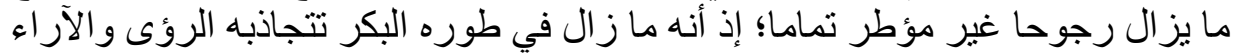

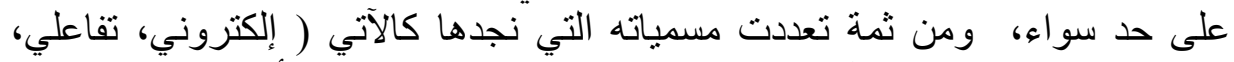

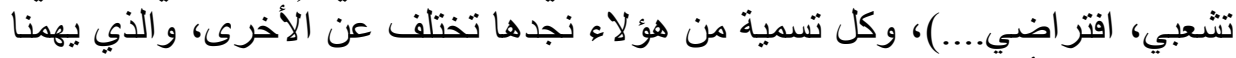

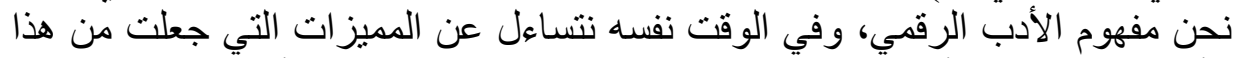

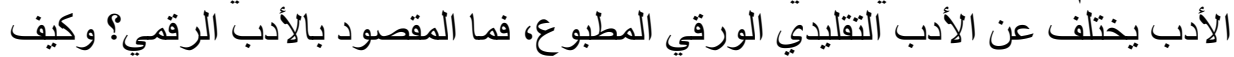

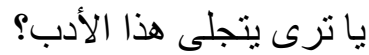
إن الحديث عن الأدب الرقمي يؤدي بنا إلى الحديث عن تطور النص الأدئ الأبي، وقد عرفته

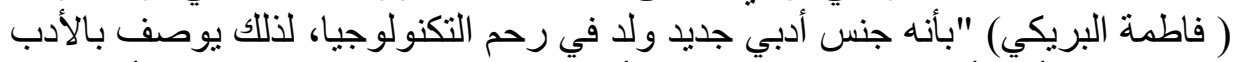

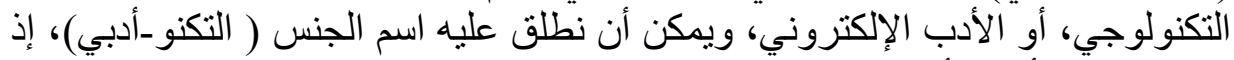

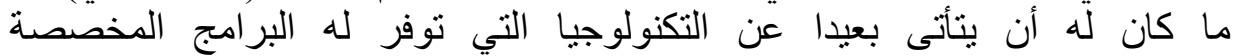

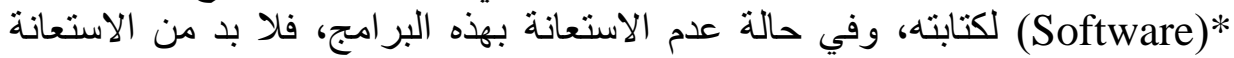

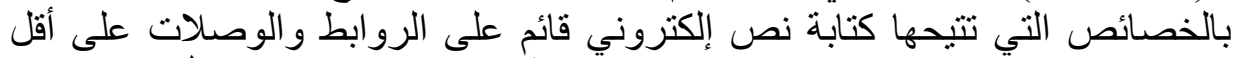

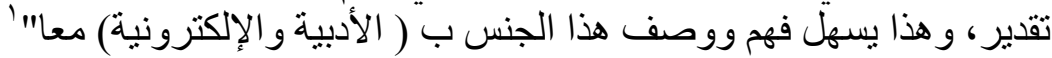

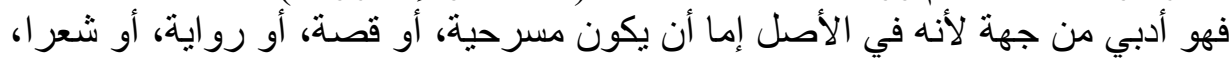

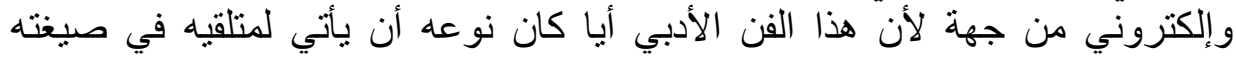

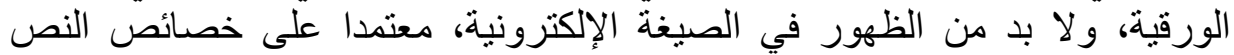

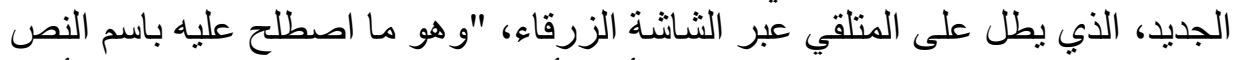

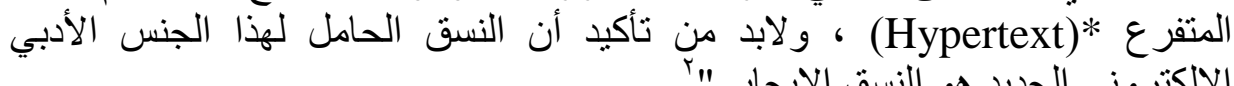
الإلكتروني الجديد هو النسق الإيجابي" النئ يتضح لناً أنه جنس أدبي جديد يجمع بين الأديبية والإلكترونية، يأتي عبر الحاسوب،

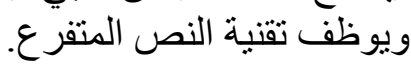




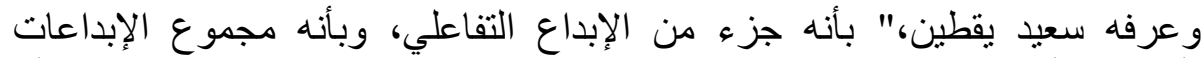

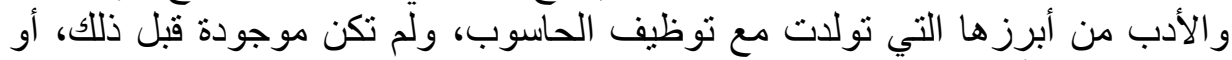

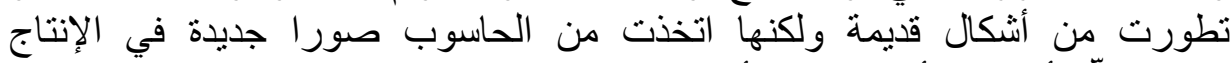

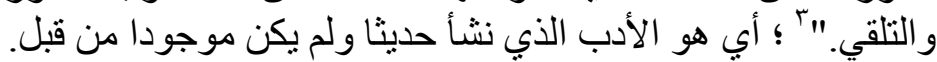

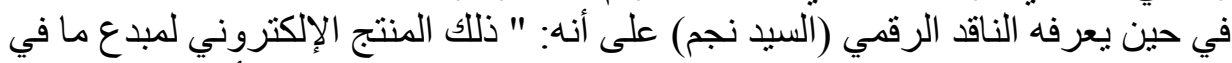

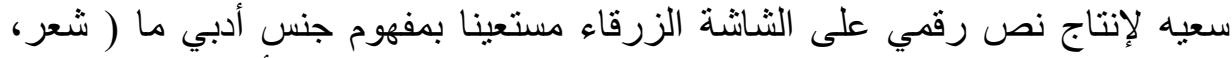

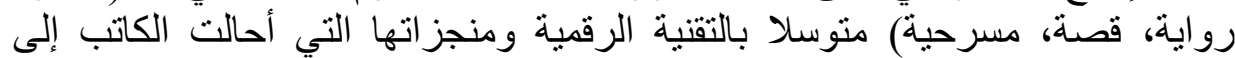

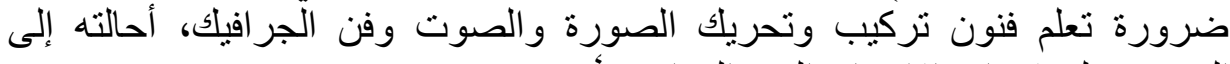

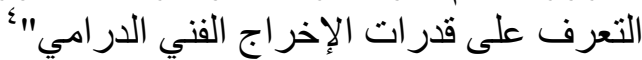

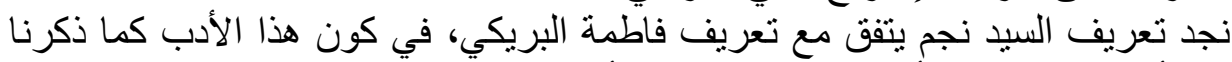

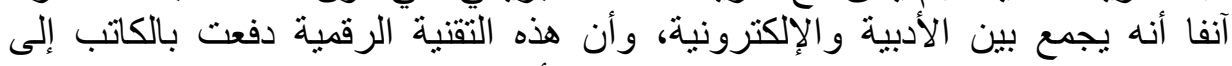

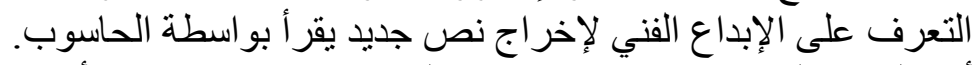

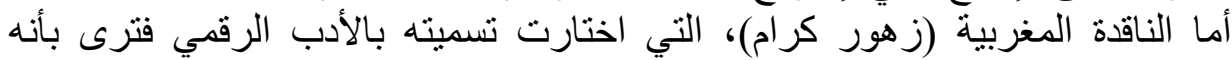

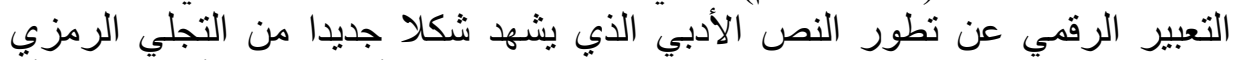

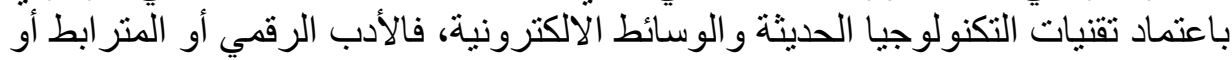

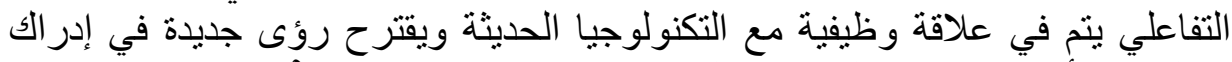

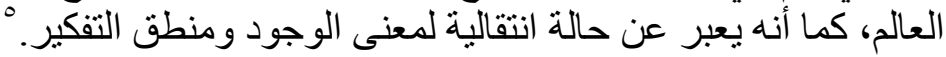

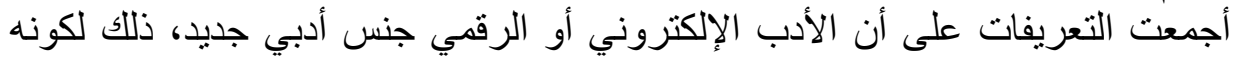

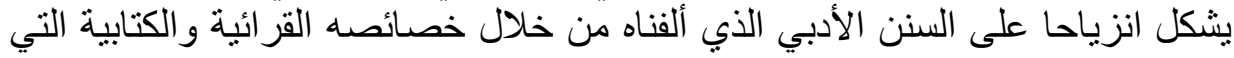

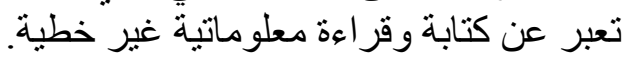

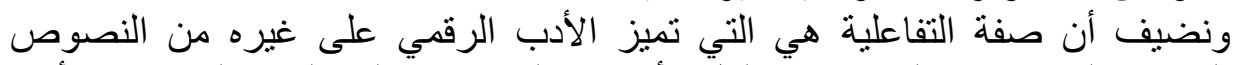

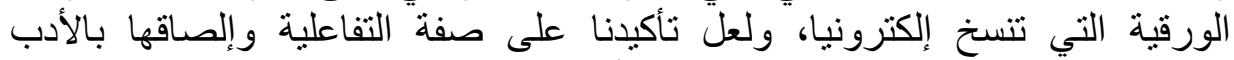

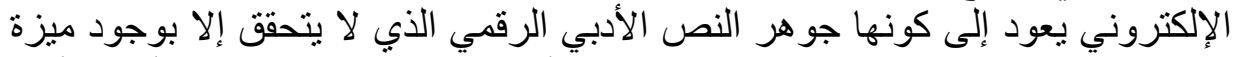

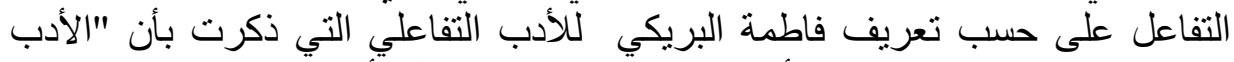

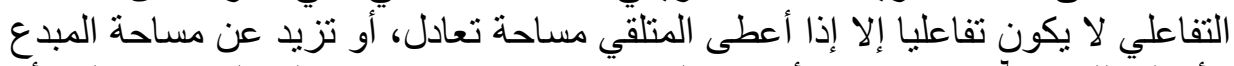

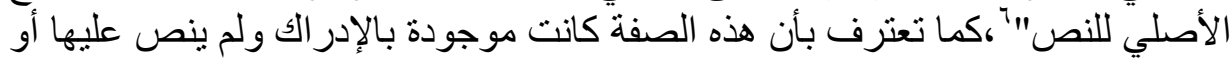

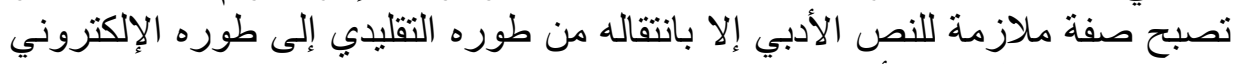

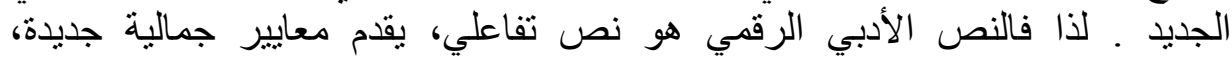

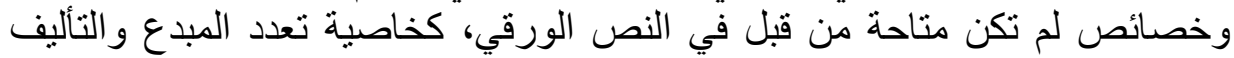

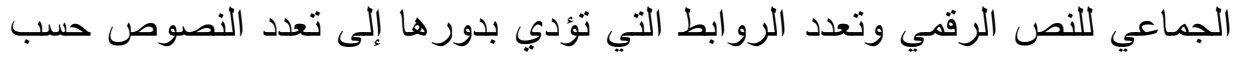
اختيار ات المتلقين. 


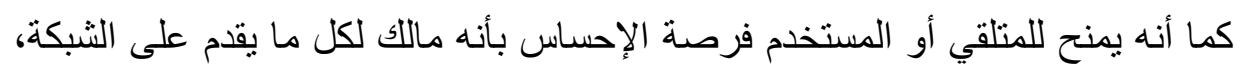

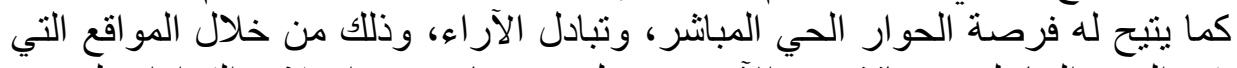

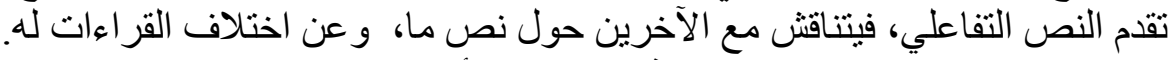

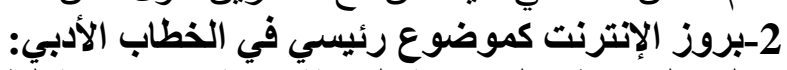

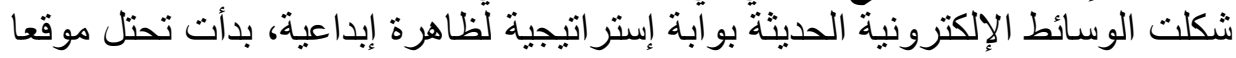

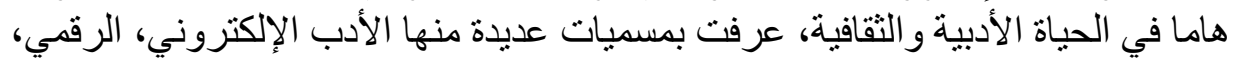

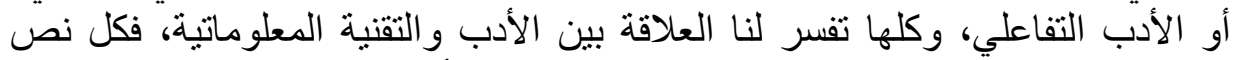

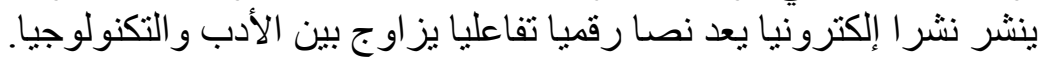

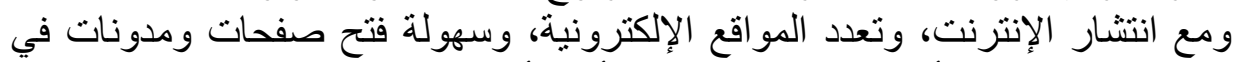

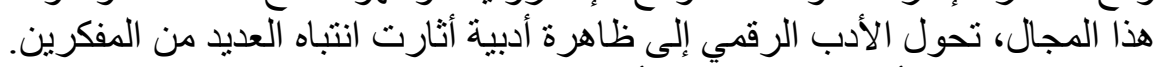

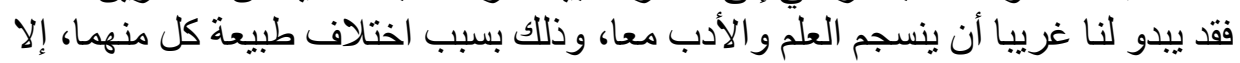

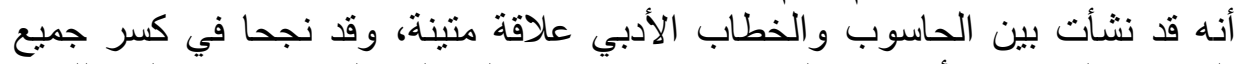

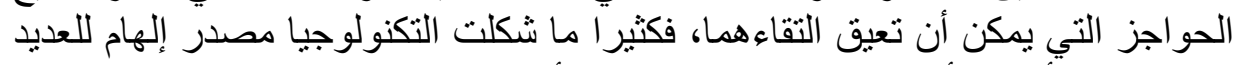

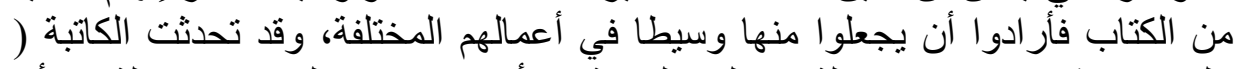

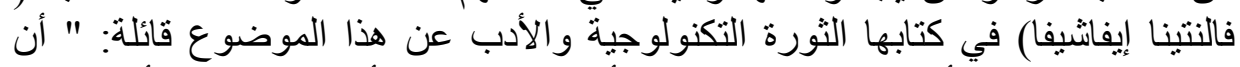

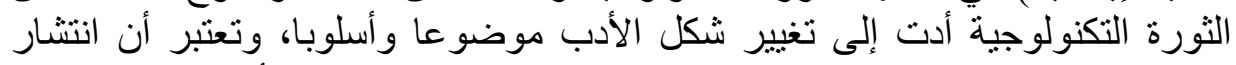

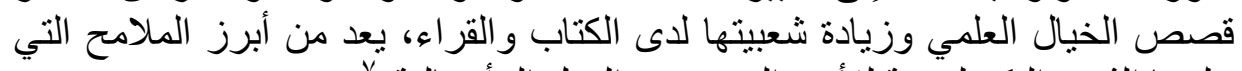

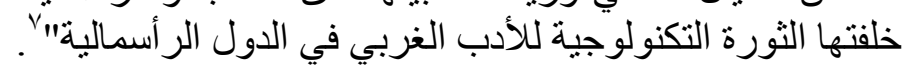

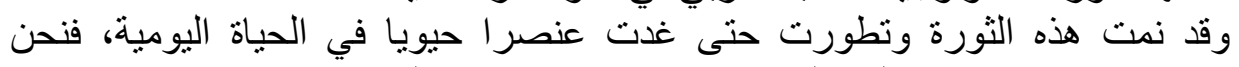

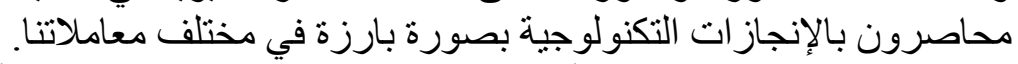

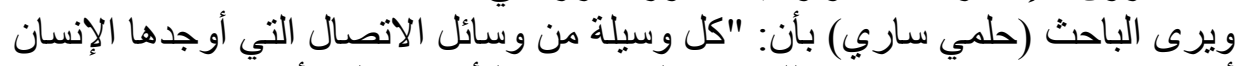

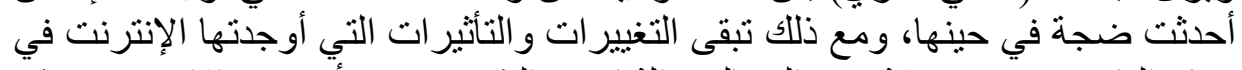

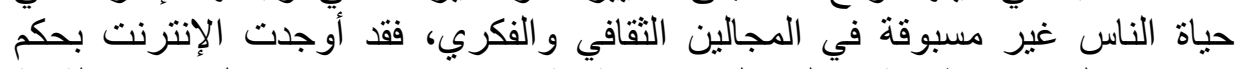

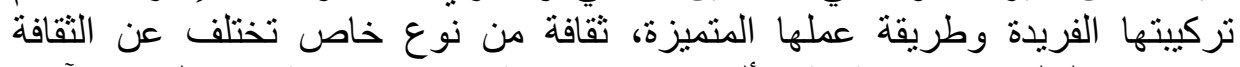

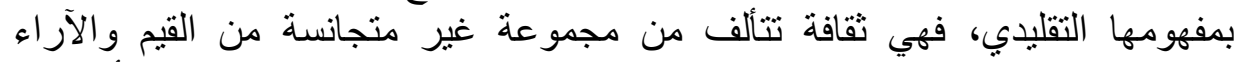

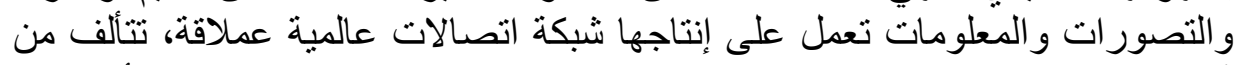

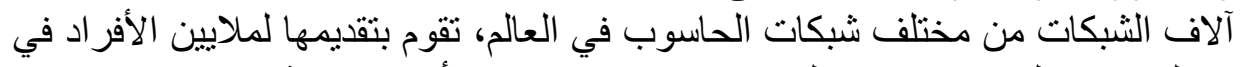

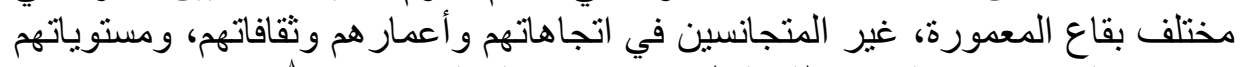

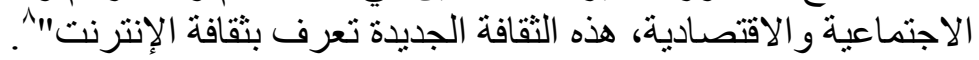

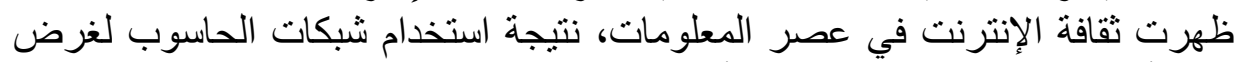

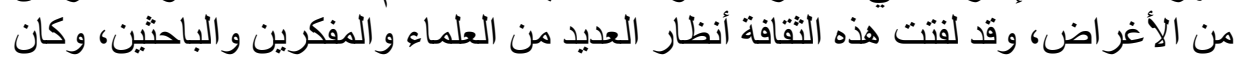

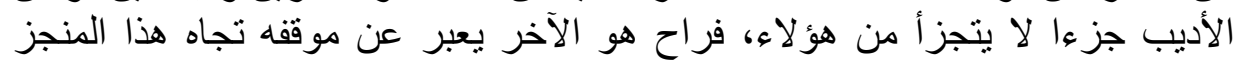




\section{د/ عبد الرحمن خليفة الملحم}

التكنولوجي الحديث، و هكذا تحولت شُبكت الإنترنت إلى موضوع رئيسي في الخطاب

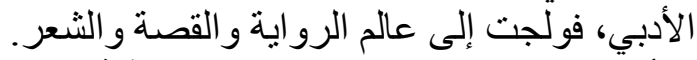

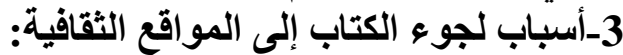

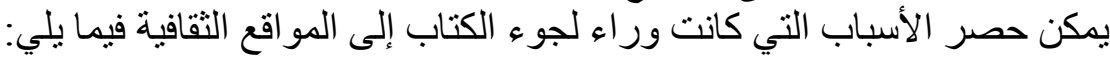

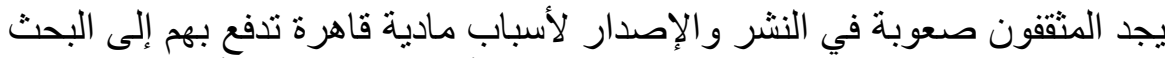

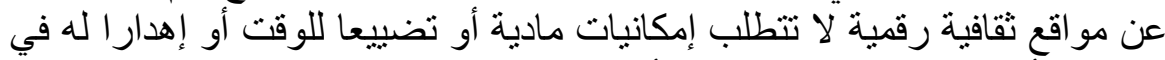

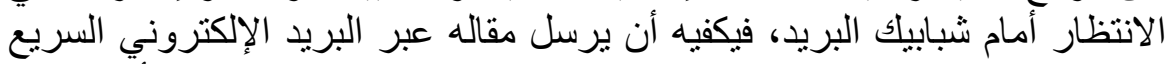
والمجاني بطبيعة الحال إلى كل المجلات الورقية والرقمية التي يفضل أن يتعامل معها. صعوبة النشر في المنابر الورقية الموجودة في البلدان التي يعيش فيها المثنقفون

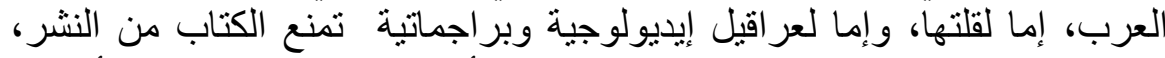

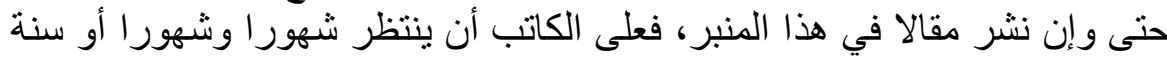

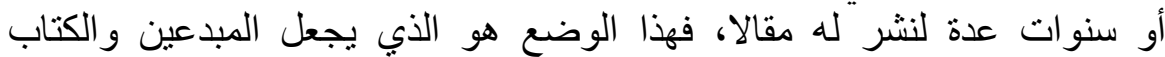

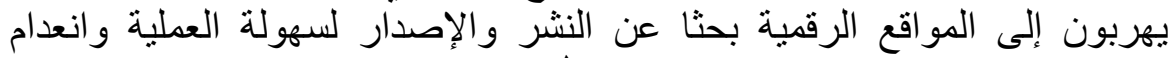

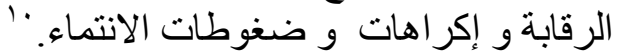

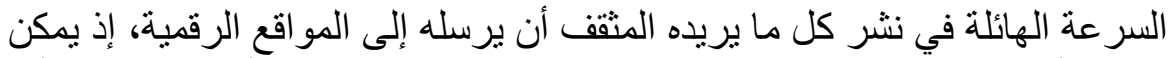

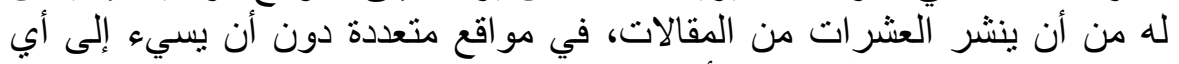

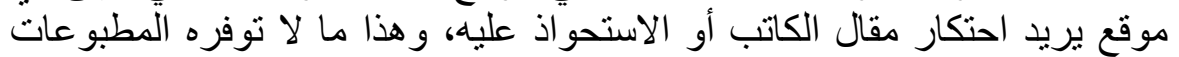

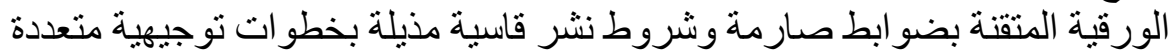

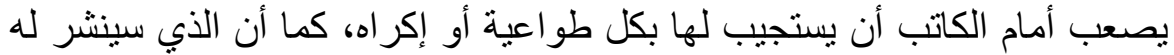

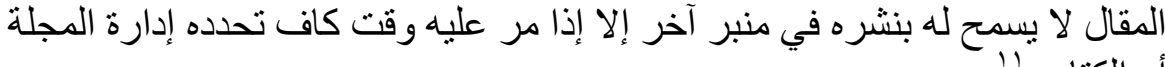

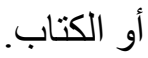

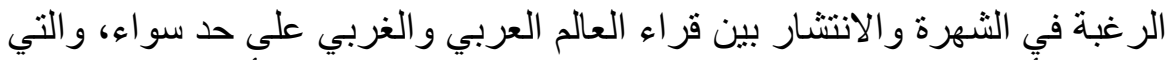

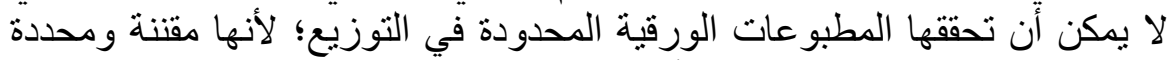

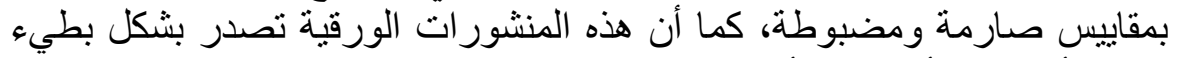

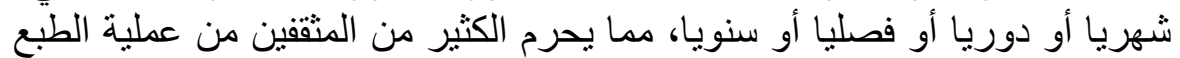

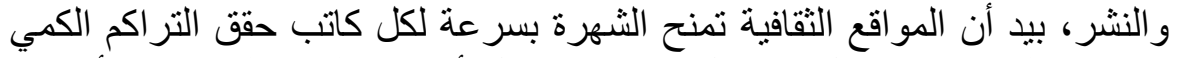

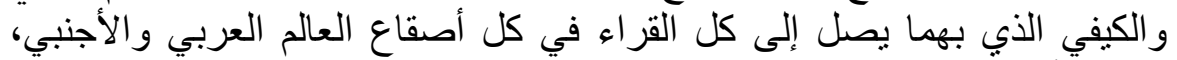

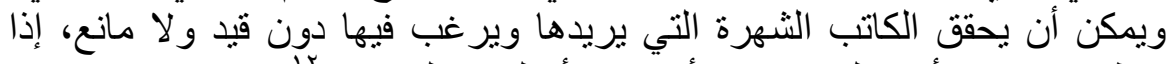

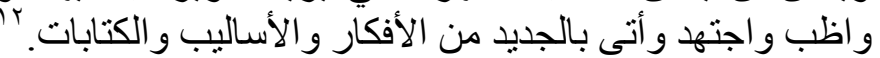

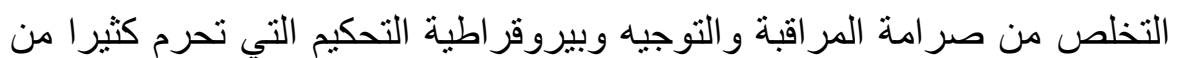
المبدعين و الدارسين من لذة النشر والإصدار، كما هو شأن بعض النيم المجلات الورقية 
التي تركز على الجودة والمعاصرة وحداثة المضمون، والدقة في التوثيق الأكاديمي

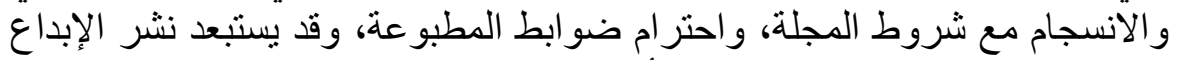

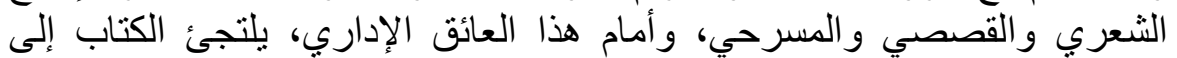

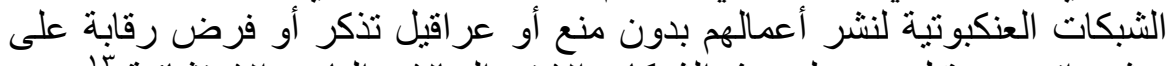

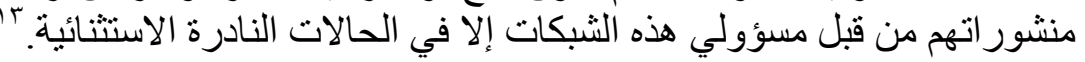

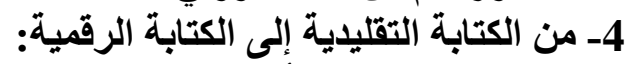

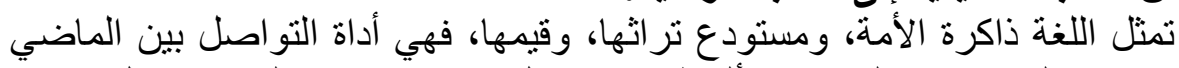

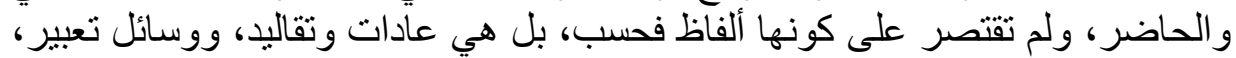

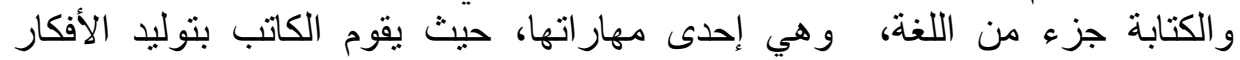

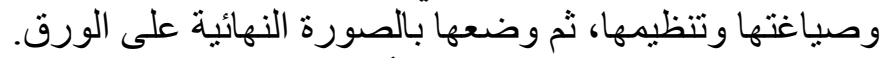

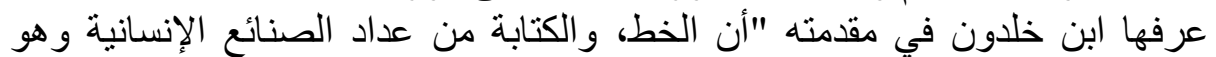

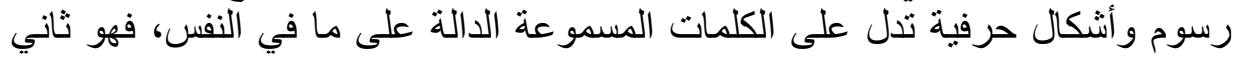

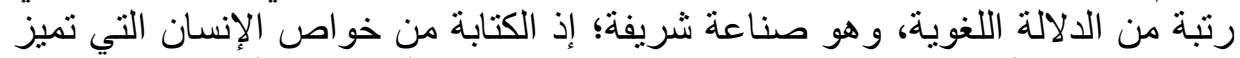

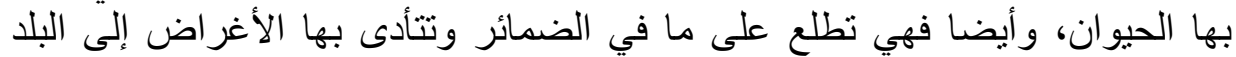

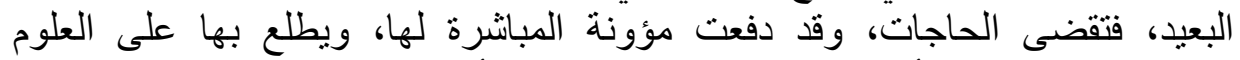

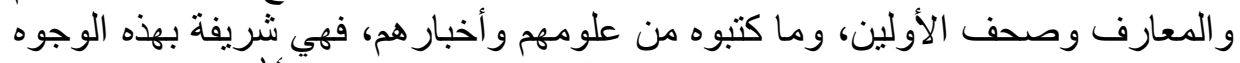

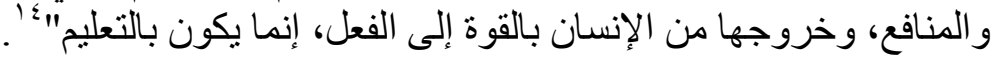

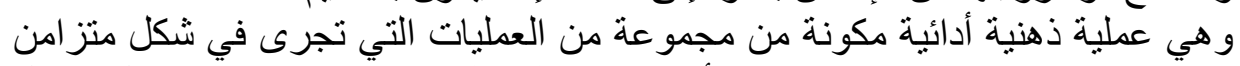

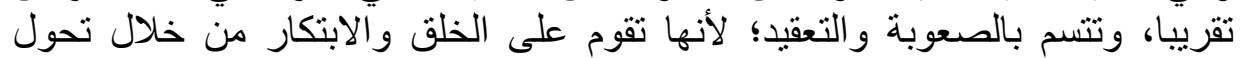

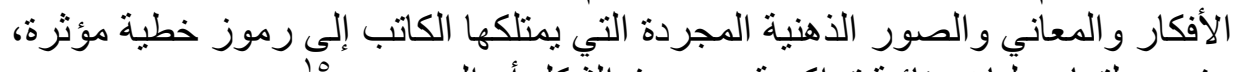

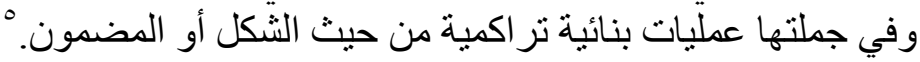

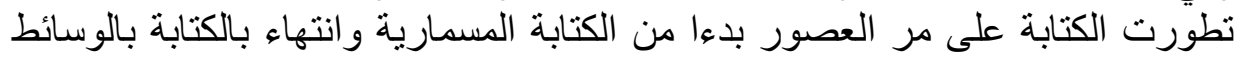

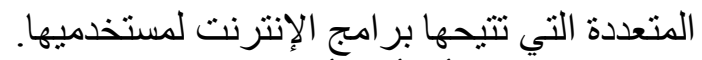

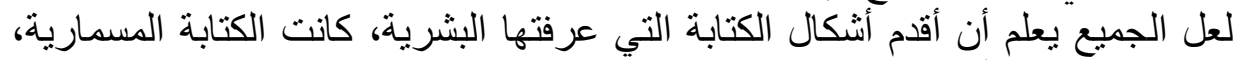

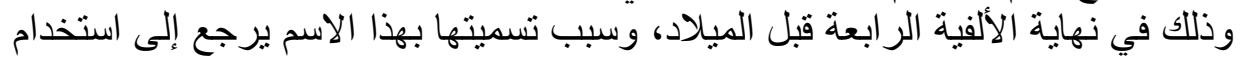

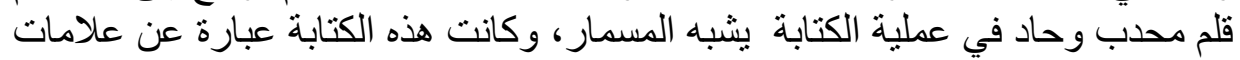

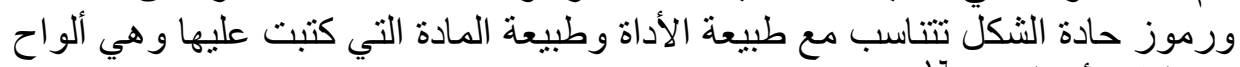

$$
\text { من الطين أو الفخار. }
$$

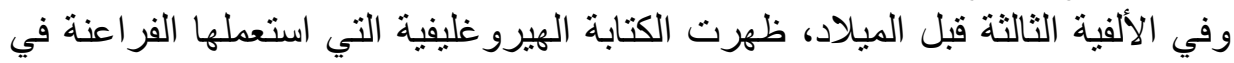

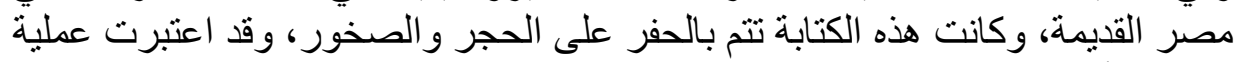

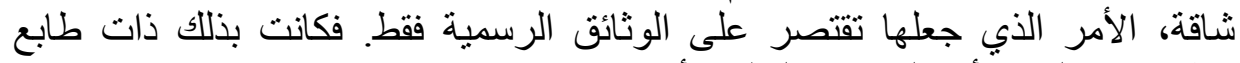
وظيفي وشكل من أثنكال الاتصال ليس أكثر. تلأنر 
د/ عبد الرحمن خليفة الملحم

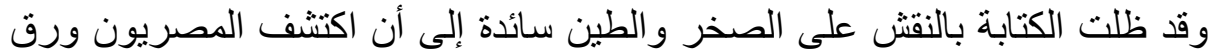
البريدي، فكان لهذا الاكتثاف تأثير على ماهية الكتابة، الأمر الذي أدى الذئ إلى إمكانية

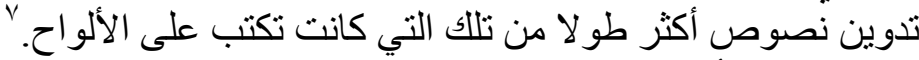

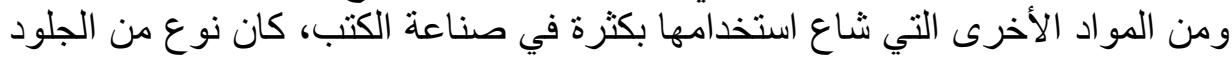

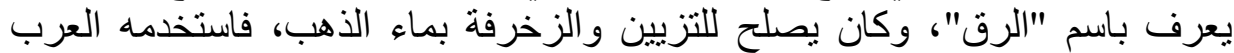

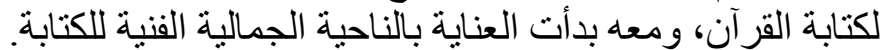

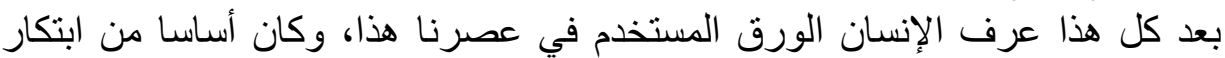

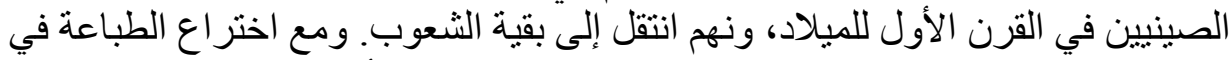

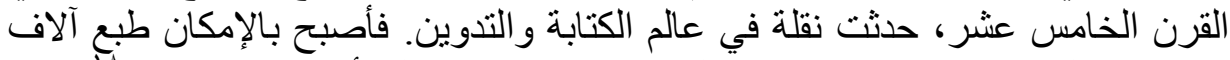

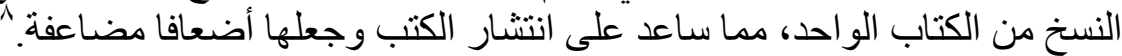

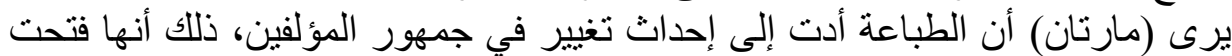

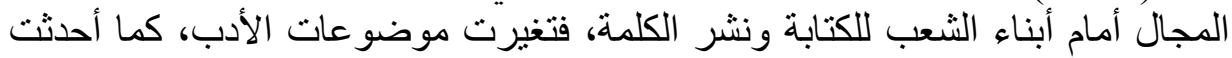

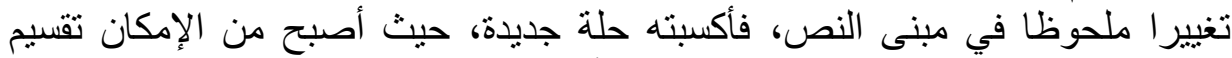

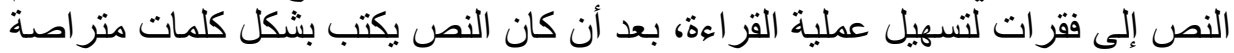

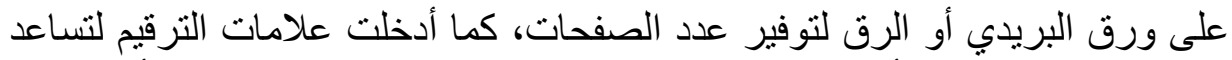

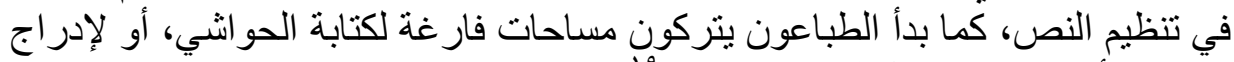

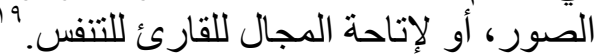

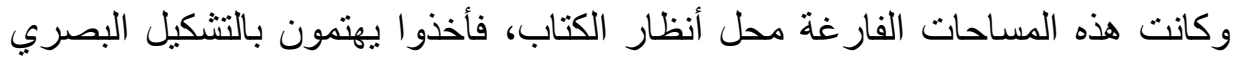

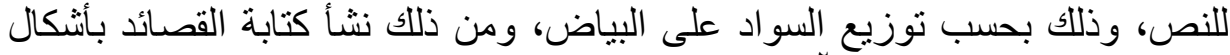

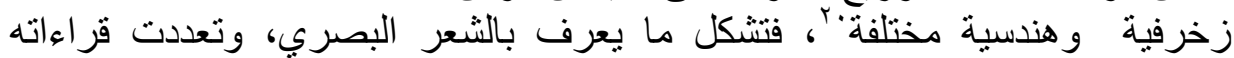

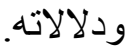

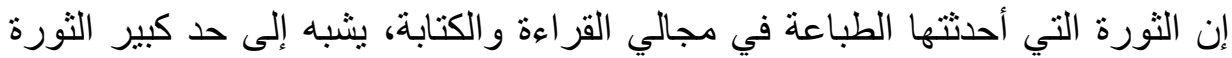

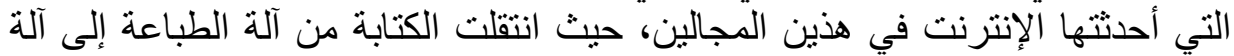

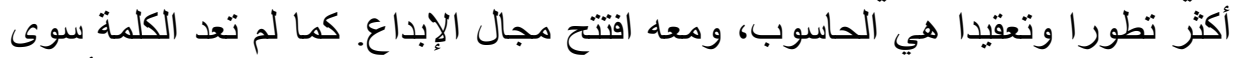

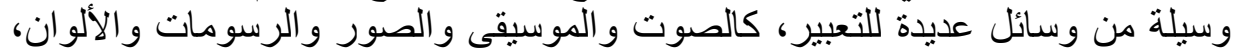

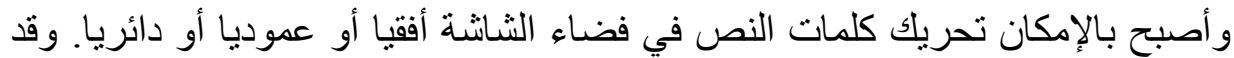

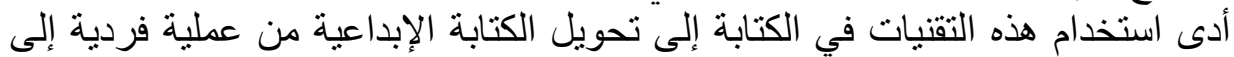

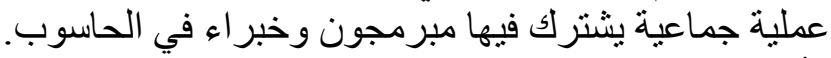

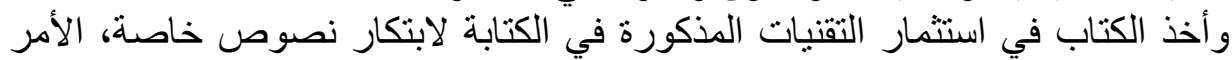

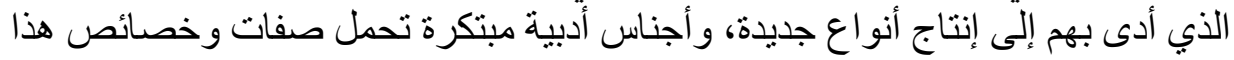

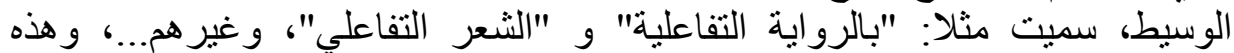
الأجناس تحتاج دائما إلى وسيط "بالكتروني تظهر من خلاله كالحأسوب، الأمر الذي دفع 
بالكتاب إلى اللجوء إلى شبكة الإنترنت لنشر أعمالهم، خاصة أن هذه الأخيرة قد أتاحت لهم استخدام بر امج مختلفة لإنتاج نصوصة الإنترنهم.

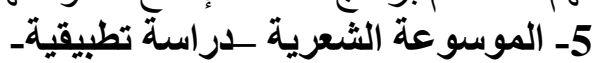

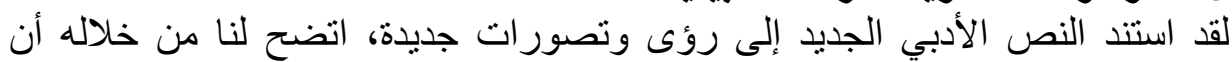

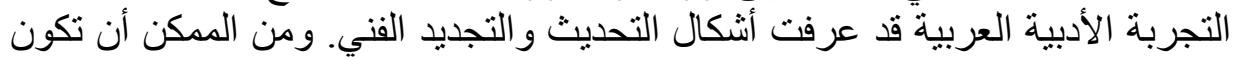

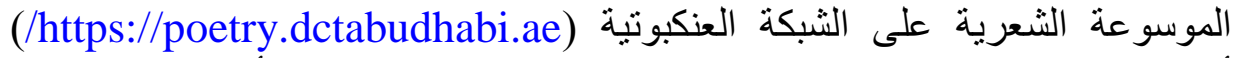

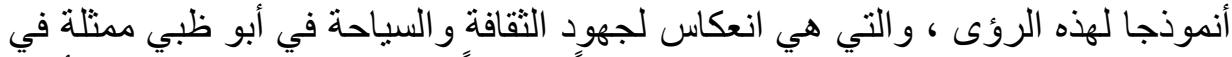

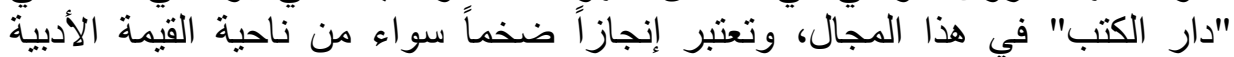

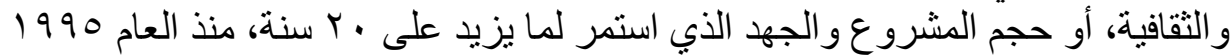

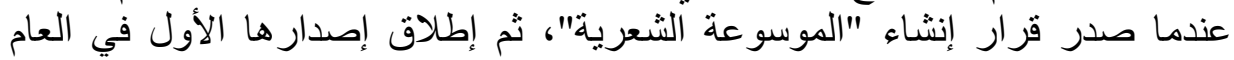

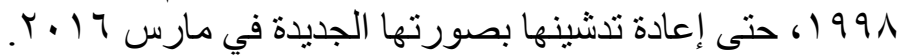

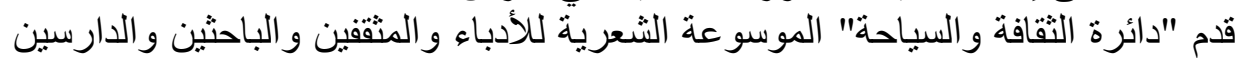

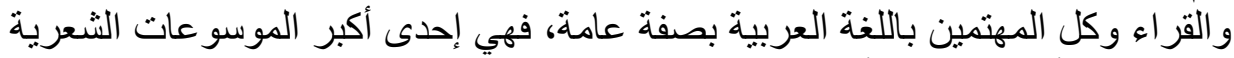

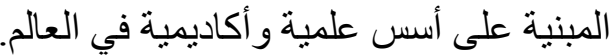

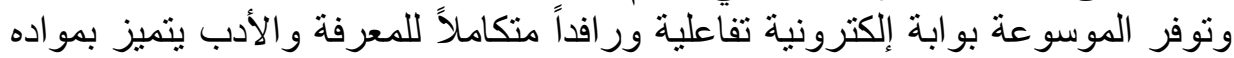

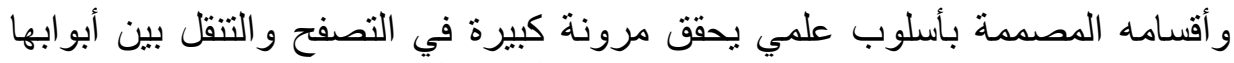

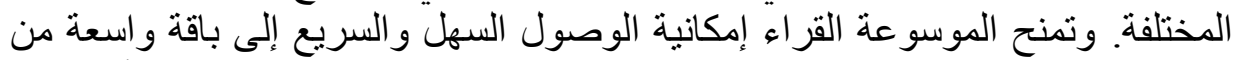

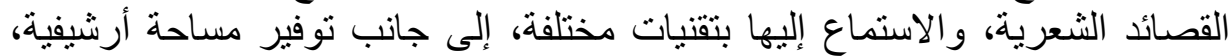
وقنوات لتدوين انطباعاتهم و آر ائهم.

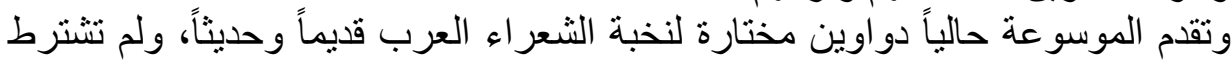

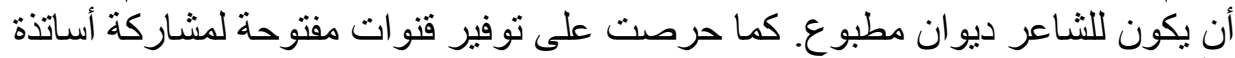

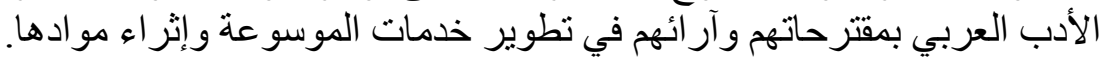

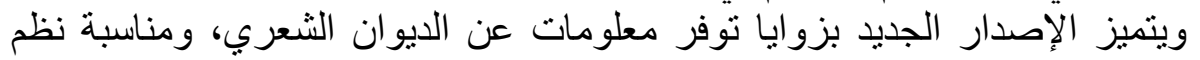

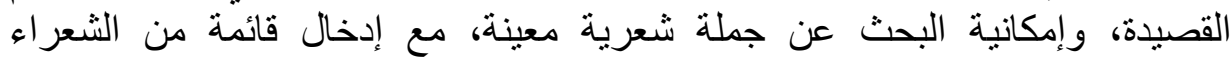

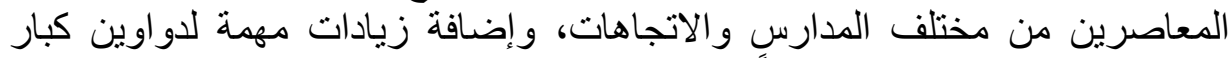

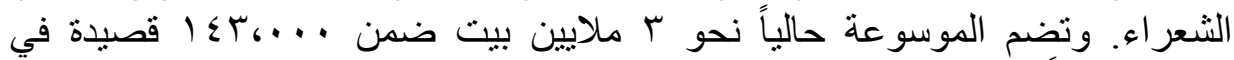

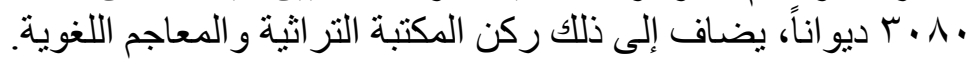

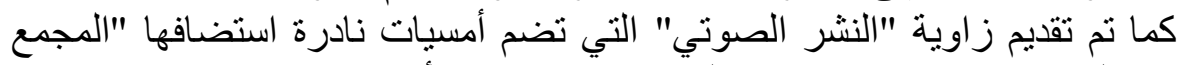

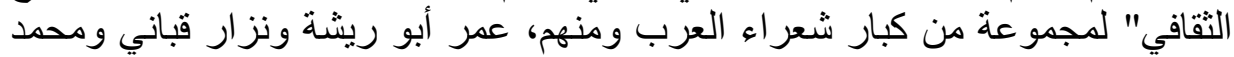

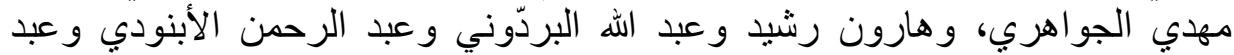

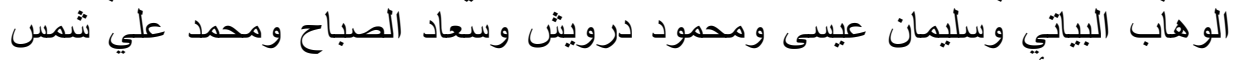
الدين ومحمد أحمد السويدي. 


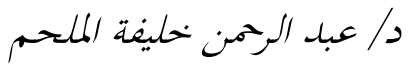

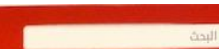

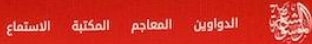

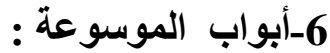

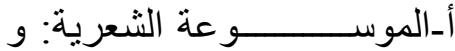

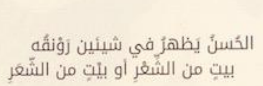

:

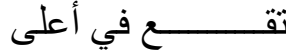

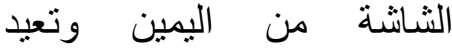
المتصفح للصفحة لألمنة الرئيسية .

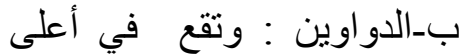

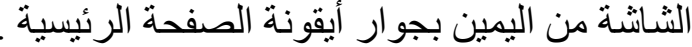

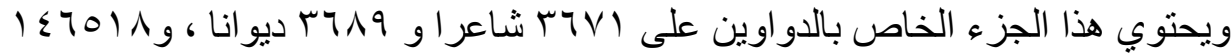

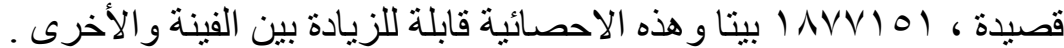

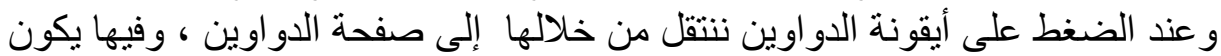

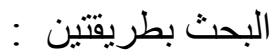
الأولى ـالبحث من خلال إدخال اسم الثاعر وتظهر من خلالها نتائج البحث على النحو

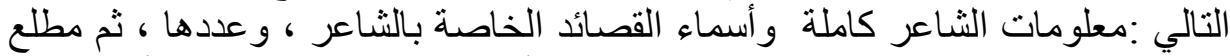

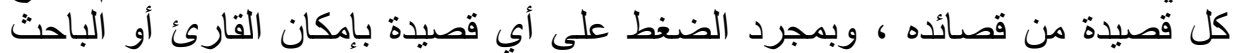

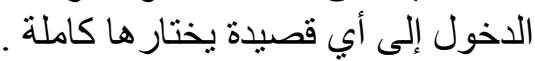

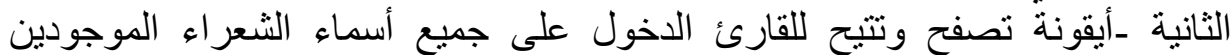

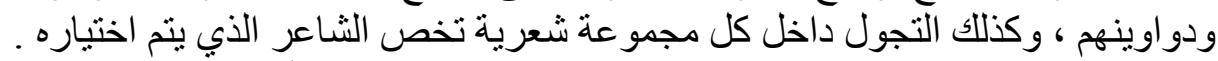

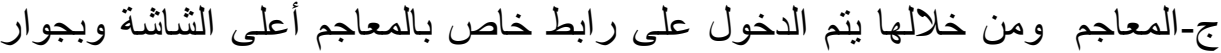

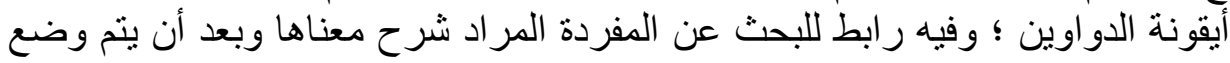

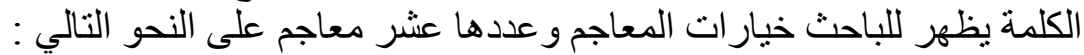

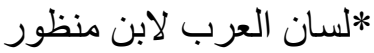

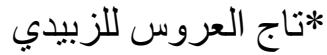
*تهذيب اللغة للأز هري الزئي * المحكم و المحيط الأعظم لابن سيدة المبر المبرسي *العباب الز اخر و اللباب الفاخر للحسن بن محمد الصغاني الصني

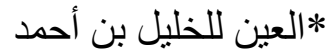

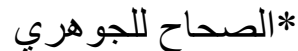
* *أساس البلاغة للزمخثري

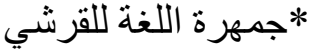
* المحيط في اللغة للصناحب بن عباد 
ويتم بعد وضع المفردة في أيقونة البحث يختار الباحث أحد هذه المعاجم أو جزء منها أو

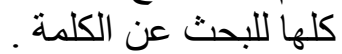

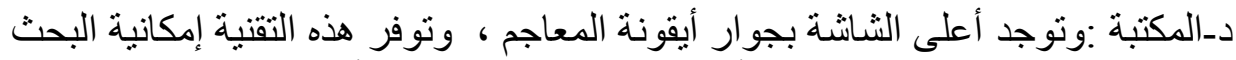

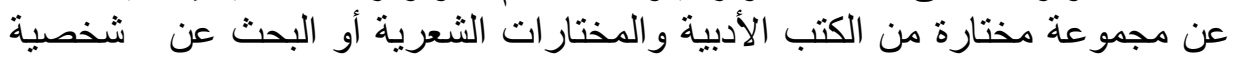

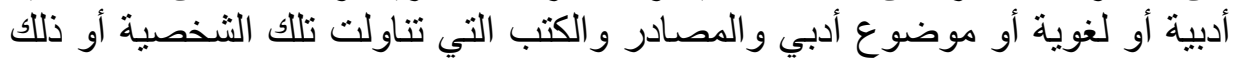

فـالاستماع: وتقع في أعلى ووسط شاثشة الموسوعة ؛ وفيها إمكانية اختيار القصائد

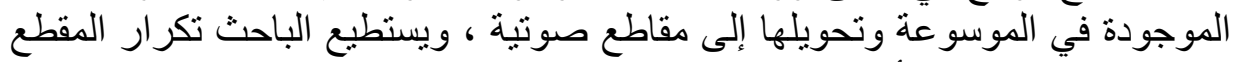

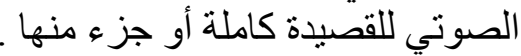

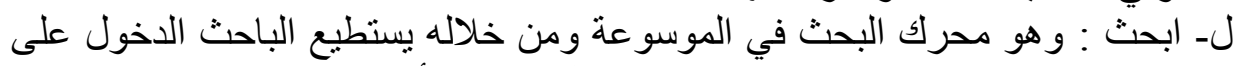

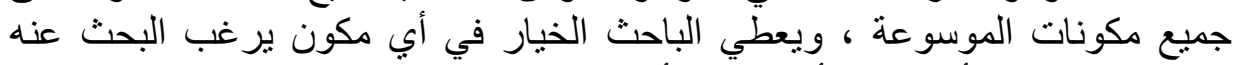

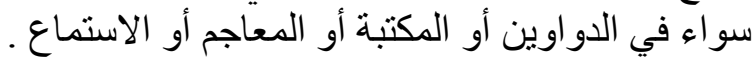

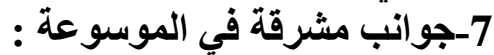

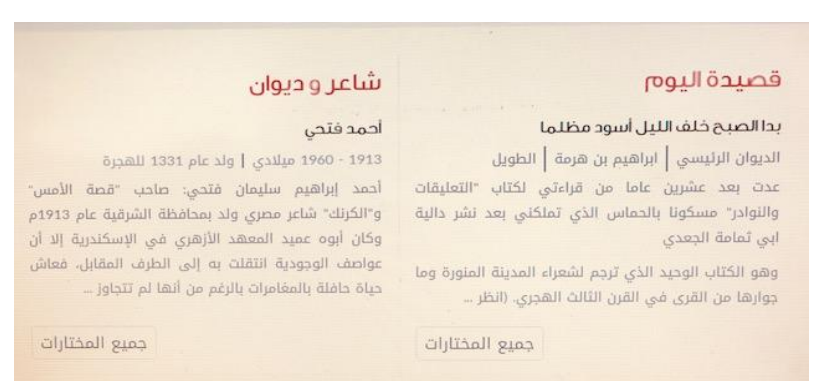
تميزت الموسوعة بعدة الموسوة

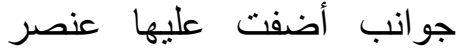

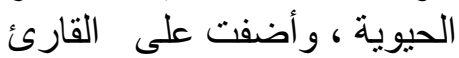

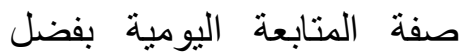

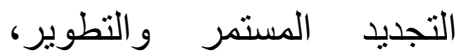

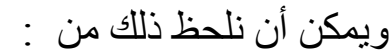

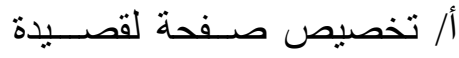

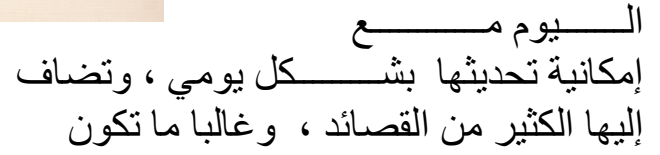

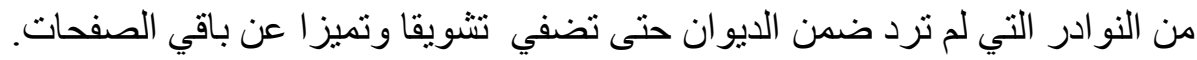

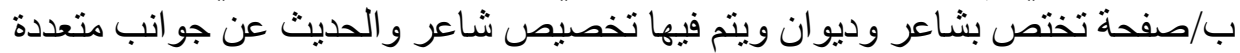

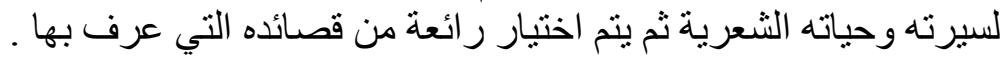

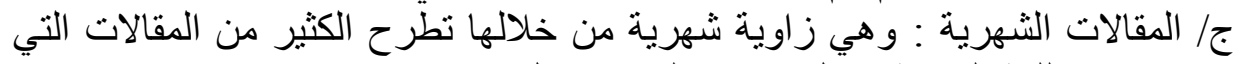

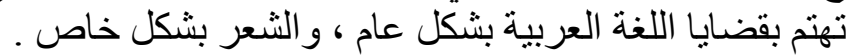

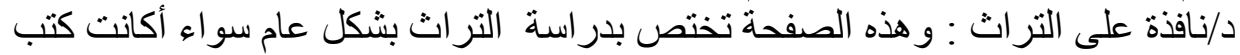

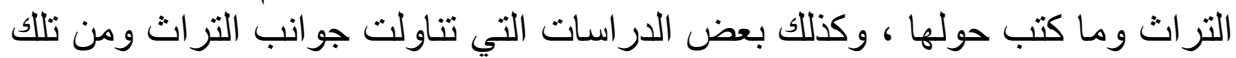

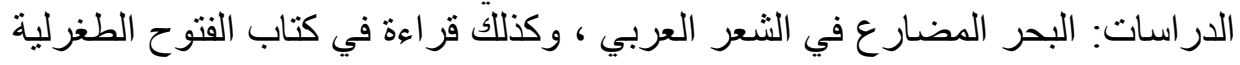




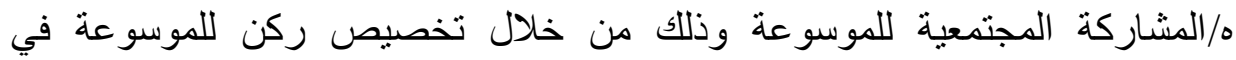

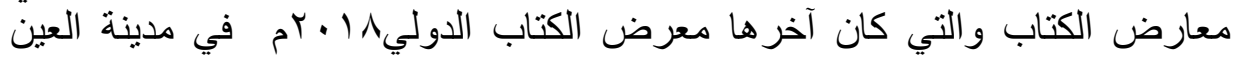
الإمار اتية . ع/الاحتفاء بالمناسبات الخاص باللغة العربة بشكل عام وبالثعر بشكل خاص وكان الإن التهاء

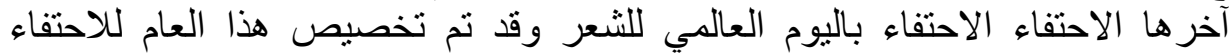

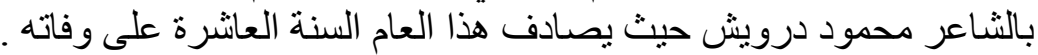

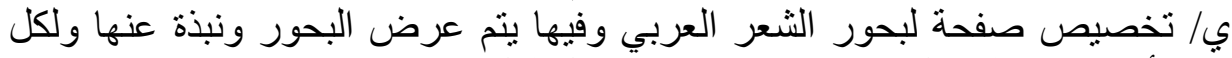

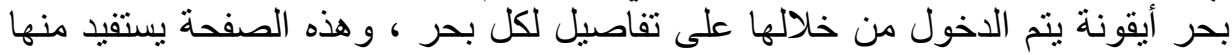

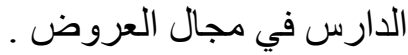

الخاتمة :

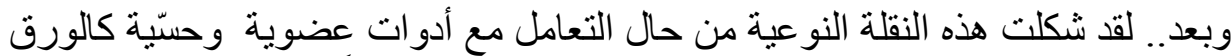

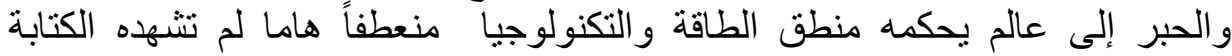

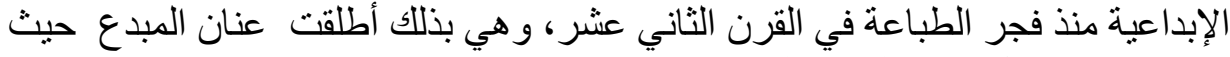

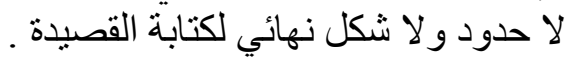

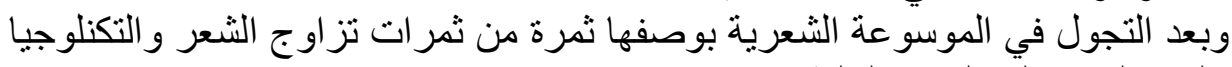

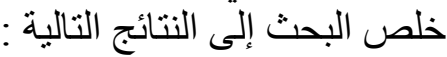

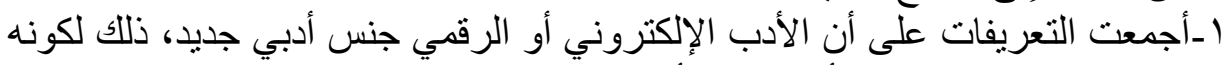

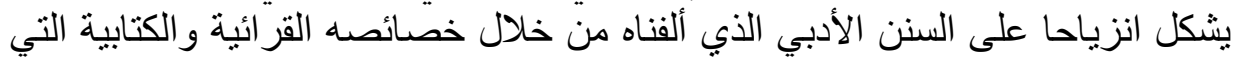

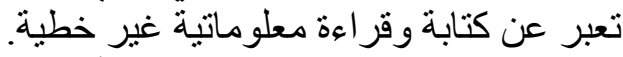

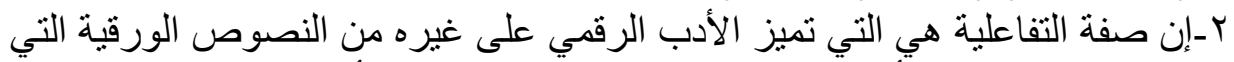

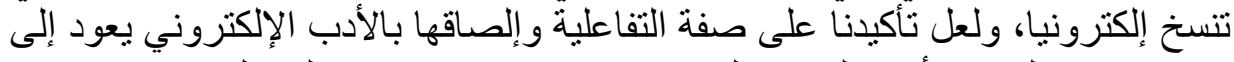

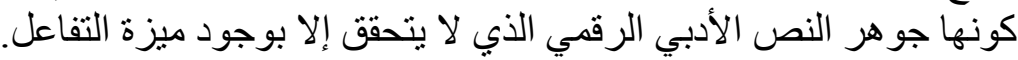

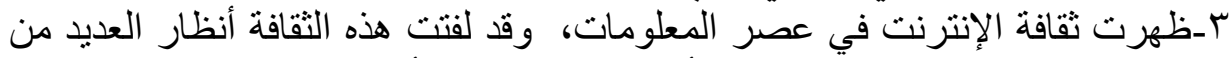

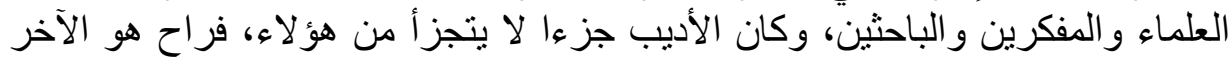

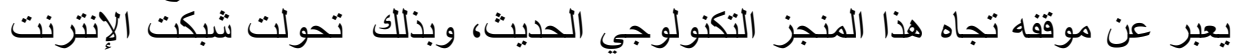

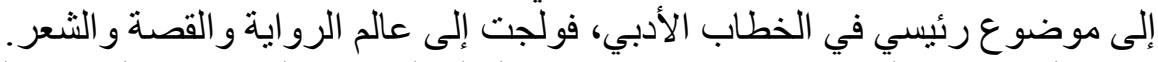

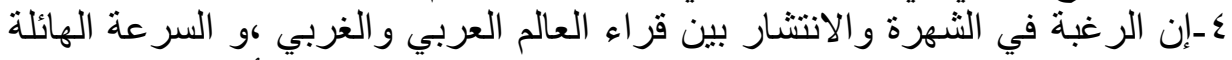

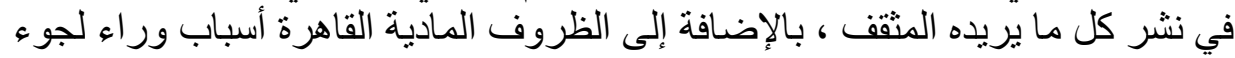
الكتاب إلى المو اقع الثقافية . 


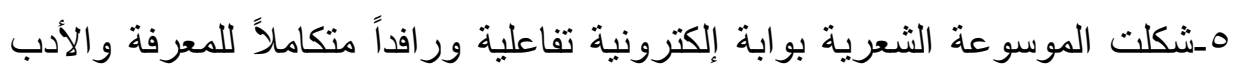
يتميز بمو اده و أقسامه المصممة بأسلوب علمي المي يحقق مرونة كبيرة في التصفح و التنقل بين أبو ابها المختلفة.

التوصيات : ا-تبني مجلة شهرية أو نصف سنوية تختص بالأدب الرقمي وتقديم الدعم اللازم لها

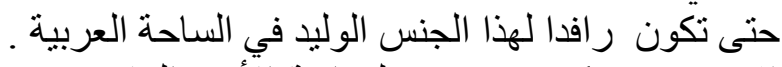

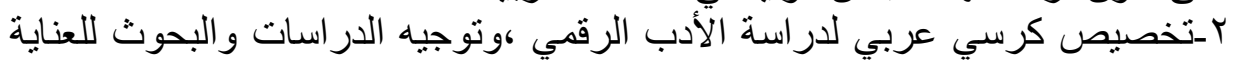

$$
\begin{aligned}
& \text { ال المهوامش: }
\end{aligned}
$$

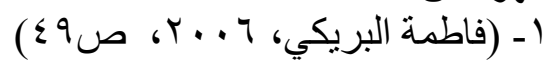

(Software)

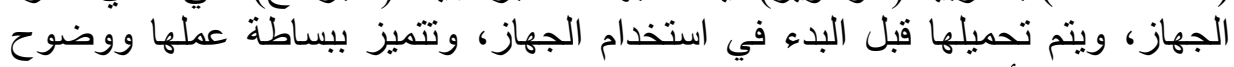

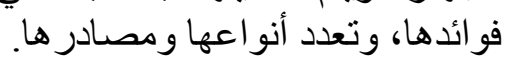
(Hypertext)

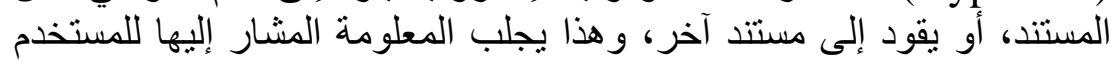

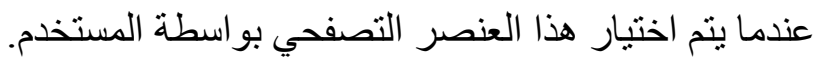

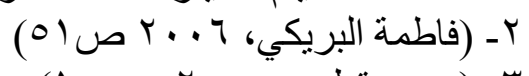
ك

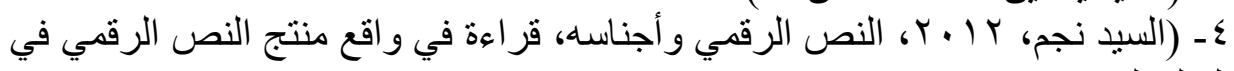

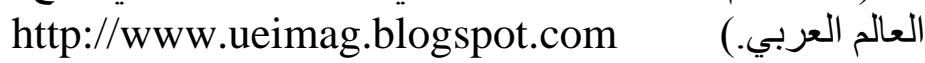

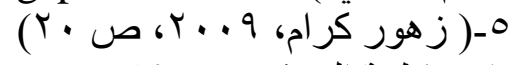

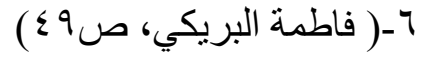

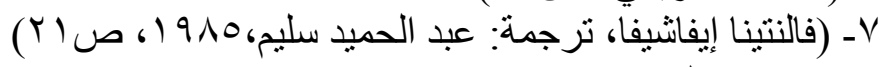

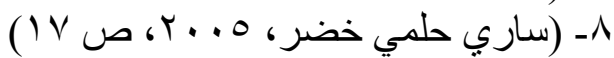

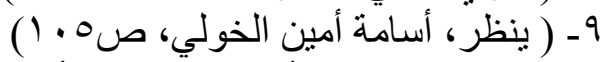

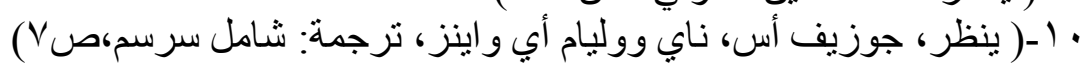

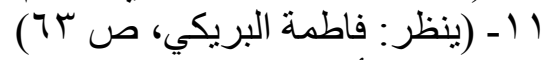

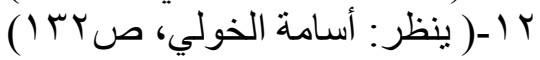

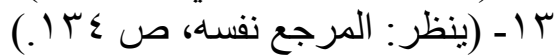

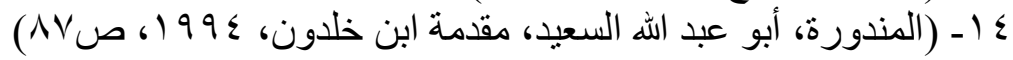

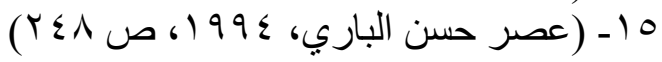
rV 
د/ عبلد الرحمن خحليفة الملحمى

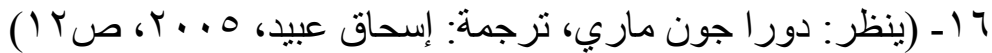

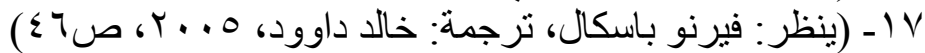

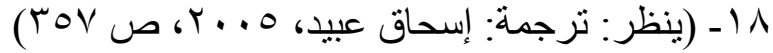

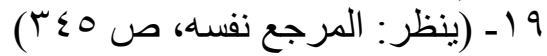

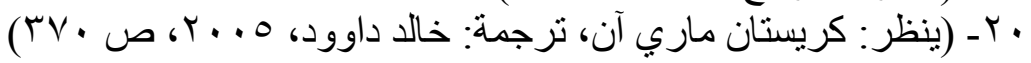

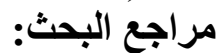

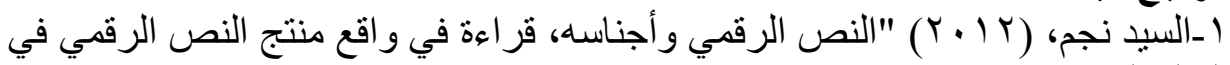

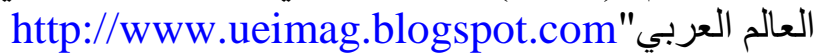
r- المندورة، أبو عبد الله السعيد،(؟ 99 (1)، مقدمة ابن خلدون، طا، مؤسسة الكتب

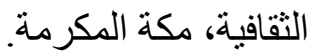

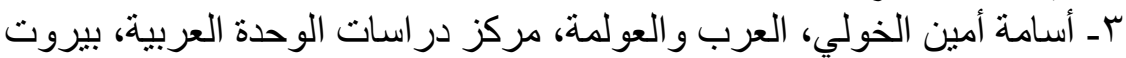

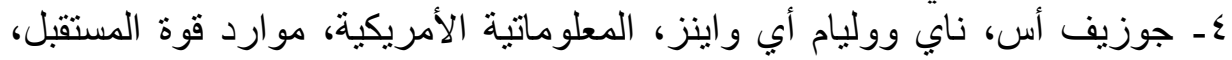

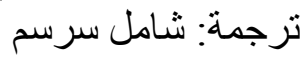

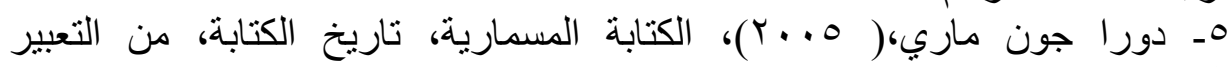

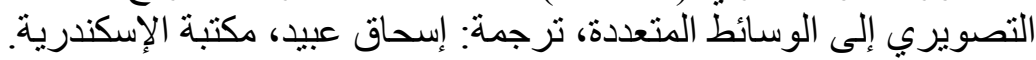

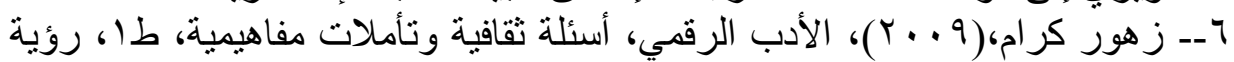

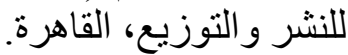

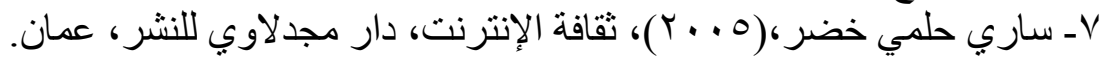

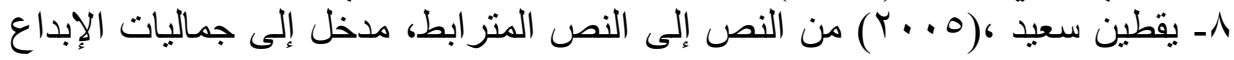

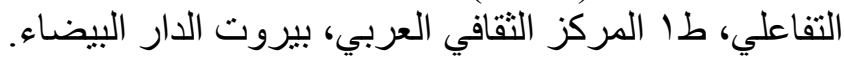

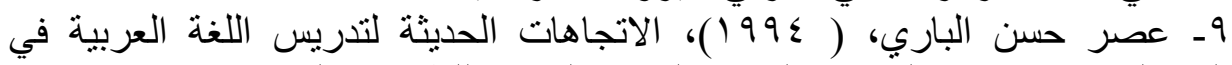

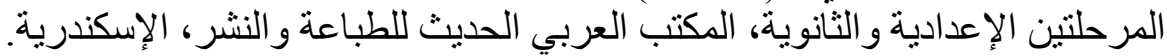

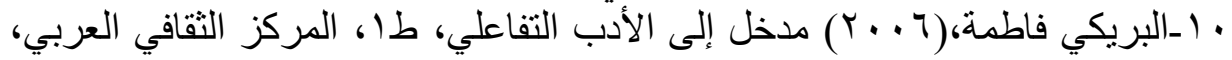

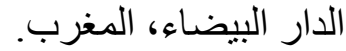

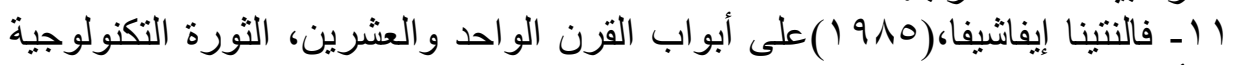

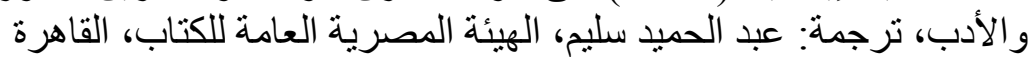

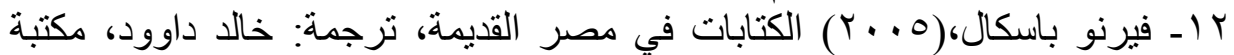

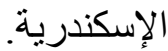

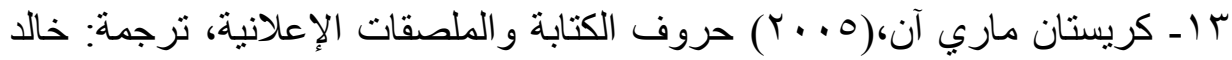
داوود، مكتبة الإسكندرية.

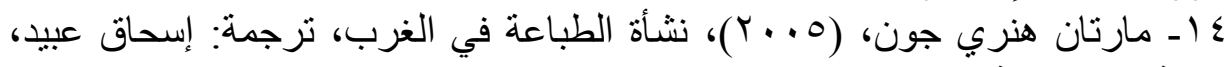

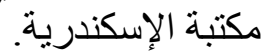

